\title{
2. RESEÑA DE SENTENCIAS
}

SUMARIO: I. ACTOS ADMINISTRATIVOS: 1. NULIDAD. 2. SUSPENSION DE ACTOS MUNICIPALES POR EL GOBERNADOR.-II. AYUNTAMIENTOS: 1. ALCALDES: FACULTAD DE SUSPENDER LAS LICENCIAS DE OBRAS. 2. AUTONOMÍA: LÍMITES. 3. AUTONOMÍA: LÍMITES: RÉGIMEN EsPecial de CARTA. 4. Concejales: baja EN El PARTido Polftico. 5. Sesiones: Comisión Permanente. 6. Quórum.-III. BIENES: RECUPERACIÓN ADMINISTRATIVA.-IV. EXPROPIACION FORZOSA: 1. DERECHO ARRENDATICIO. 2. JURADO: VALOR DE SUS ACUERDOS. 3. RETASACIÓN.-V. FARMACIAS: SUSPENSIÓN DE LA EJECUCIÓN DEL ACTO QUE ORDENA SU CIERRE.-VI. FUNCIONARIOS: 1. CONVENIO COLECTIVO: FUNCIONARIOS PÚBLICOS: INAPLICACIÓN. 2. APAREJADORES: INCOM PATIBILIDADES.-VII. HACIENDAS LOCALES: 1. ARbitrio de plusvalía: eXPlotación forestal. 2. ARbiTRIO DE PLUSVALfA: EXPLOTACIÓN GANADERA.-VIII. JURISDICCION CONTENCIOSO-ADMINISTRATIVA: 1. CORPORACION LOCAL: DICTAMEN PREVIo DE LeTrado. 2. "Solve ET REPETE».-IX. POLICIA MUNICIPAL: 1. ACTIVIDADES MOLESTAS, INSALUBRES, NOCIVAS Y PELIGROSAS: MEDIDAS CORRECTORAS: SALIDA DE EMERGENCIA. 2. LICENCIAS: COMPETENCIA MUNICIPAL. 3. LICENCIAS DE OBRAS: PROCEDIMIENTO. 4. LICENCIAS DE OBRAS: SUSPENSIÓN POR EL ALCALDE. 5. OBRAS SIN LICENCIA: DEMOLICIÓN. 6. RUINA: CONCEPTO. 7. RUINA: CLASES. 8. RUINA: MEDIOS NO NORMALES DE REPARACIÓN. 9. RUINA URBANÍSTICA.-X. PROCEDIMIENTO ADMINISTRATIVO: AUDIENCIA DE LOS INTERESADOS EN EL EXPEDIENTE.-XI. RESPONSABILIDAD: DE LA ADMINISTRACIÓN LOCAL.-XII. SERVICIOS: 1. RECOGIDA DE BASURAS: RESOlUCIÓN DE CONTRATO. 2. TELÉFONOS: facultades de la Compañfa Telefónica Nacional de EspaÑa y de los AyUNTAMIENTOS.-XIII. TERMINOS MUNICIPALES: DESLINDES.-XIV. TRAFICO: ESCUELAS DE CONDUCTORES: LUGARES PARA PRACTICAS.-XV. URBANISMO: 1. ESTUDIO DE DETALLE: NO SON IMPUGNABLES. 2. LiCENCIA QUE INFRINGE EL PLAN: SUSPENSIÓN. 
3. Revisión del Plan general: facultades municipales.-XVI. VIVIENDA: FACUlTadeS dE las Delegaciones PROVinciales: asceNSORES.

\section{ACTOS ADMINISTRATIVOS}

\section{NULIDAD}

Enseña la jurisprudencia - sentencias, entre otras, las de fecha 6 de febrero de 1968, 27 de enero y 19 de junio de 1969, 16 de marzo de 1970, 14 de abril de 1971, 29 de mayo de 1972, 20 de abril de 1976 y 27 de febrero de 1978-que la teoría juridica de la nulidad de los actos administrativos ha de aplicarse con especial moderación y cautela, debiendo sólo considerarse para causar dicho efecto, gravisimas y sustanciales infracciones legales, a no ser que resultase quebrantado el sagrado derecho de defensa de los interesados, conclusión que no puede ni debe predicarse si éstos han utilizado los recursos administrativos y la vía jurisdiccional, pues lo contrario seria incurrir en un exceso dogmático que conduciría, en el futuro, a un acto de igual contenido, lo que sería contrario a los efectos derivados del principio de economía procesal, como recuerdan, entre otras, las sentencias de 25 de mayo de 1973 y 4 de mayo de 1978. (Sentencia de 8 de marzo de 1983, Ar. 1386.)

\section{SUSPENSIÓN DE ACTOS MUNICIPALES POR EL GOBERNADOR}

Del análisis de los artículos 362 a 366 de la Ley de Régimen local, se desprende, incuestionablemente, dos consecuencias: a) que la autoridad gubernativa, a la hora de decidir la suspensión de los actos o acuerdos de las Corporaciones locales, no puede elegir a su arbitrio uno y otro de los dos caminos a que nos hemos referido, sino que necesariamente debe acudir a la vía que le señalan en cada caso los preceptos indicados; b) que el caso $4 .^{\circ}$ del artículo 362 de la Ley - "cuando constituyan infracción manifiesta de las leyes"- no puede ser en modo alguno una especie de cajón de sastre al que, en definitiva, vayan a parar los otros tres primeros casos de dicho articulo, sino que, por el contrario, tiene su sustantividad propia, perfectamente perfilada por la jurisprudencia del Tribunal Supremo; de manera que aun cuando ambas vias vayan a parar a la contencioso-administrativa, la primera, la de los tres primeros casos del artículo 362, ofrece un recurso de alzada del que carece la segunda, $y$ de esta opción procesal no puede privarse a quien se estime perjudicado por la suspensión acordada. (Sentencia de 13 de enero de 1983, Ar. 257.) 


\section{AYUNTAMIENTOS}

\section{Alcaldes: facultad de SUSPENDER LAS LiCENCIAS DE OBRAS}

CONSIDERANDo: Que las licencias de construcción concedidas por las Comisiones Provinciales de Urbanismo, a través del cauce subrogatorio del artículo 9 del Reglamento de Servicios, tienen como única finalidad remediar el silencio de la Administración municipal, y ello hace que cumplida dicha finalidad deban considerarse sometidas al mismo régimen de impugnación establecido para las licencias de procedencia municipal por tener idéntica naturaleza que éstas, y así lo dispone de manera expresa el artículo 220 del Texto Refundido citado al establecer que las decisiones adoptadas, entre otros órganos, por las Comisiones Provinciales de Urbanismo en subrogación de la competencia municipal, se considerarán como actos de la Corporación titular, "a los solos efectos de los recursos admisibles", entre los cuales se incluye, aunque sea especial, el procedimiento del mencionado artículo 118 de la Ley Jurisdiccional, que se inicia con el ejercicio de la facultad de suspensión conferida al Alcalde por los artículos $186 \mathrm{del}$ mismo Texto Refundido y 34 del Reglamento de Disciplina Urbanistica, los cuales la regulan en términos de generalidad sin condicionamiento alguno en razón al órgano administrativo de quien procedan las licencias, sin que pueda por ello afirmarse que ese órgano resulte así fiscalizado por el Alcalde, pues éste se limita a producir el presupuesto previo que determina la puesta en marcha de un proceso donde es el poder judicial el que, en uso de su jurisdicción, realiza esa fiscalización en la que se hace preciso no confundir el órgano que ejerce la competencia municipal de concesión de licencias de obras - normalmente distinta al Alcaldecon aquel en que se residencia la referida facultad de suspensión y al cual no puede imponerse una restricción que no viene expresamente prevista en la Ley y que es contraria al beneficio juridico que supone la potenciación de defensa de la legalidad urbanística. (Sentencia de 15 de marzo de 1983, Aranzadi 1437.)

\section{Autonomía: limites}

Considerando: Que esta Sala viene declarando con reiteración - sentencias de 21 de mayo, 1 y 3 de junio y 16 de julio de 1982- que el principio de autonomía de los Municipios, consagrado en los artículos 137 y 140 de la Constitución Española, es compatible con la existencia de un control de la legalidad sobre el ejercicio de las competencias a los mismos atribuidas, si bien tal control ha de referirse a supuestos en que el ejercicio de las competencias de la Entidad local incida en intereses generales concurrentes con los de la propia Entidad interesada; en este sentido declara la sentencia del Tribunal Constitucional de 29 de abril de 1981 que "el artículo 365, 1, en relación con el $362,1,4 .^{\circ}$, de la Ley de Régimen local, Texto Refundido de 24 de junio de 1955, no se ajusta a la Constitución en la parte que permite que la facultad. 
de suspensión de los acuerdos de las Corporaciones locales proceda por la sola infracción manifiesta de las leyes, sin la concurrencia de otra circunstancia, pero sí se ajusta a la Constitución interpretado en el sentido de que confiere una facultad gubernativa para suspender acuerdos que afecten a la competencia del Estado o excedan del limite de la competencia propia para la gestión de los intereses de la Entidad local». (Sentencia de 9 de febrero de 1983, Ar. 815.)

\section{Autonomía: límites: Régimen Especial de Carta}

Considerando: Que como esta Sala viene declarando, entre otras, en sus sentencias de 21 de mayo, 1 y 3 de junio y 16 de julio de 1982, el principio de autonomía de los Municipios que consagran los artículos 137 y 140 de la Constitución, es compatible con la existencia de un control por parte de la Administración central de la legalidad en que se desenvuelve el ejercicio de las competencias a los mismos atribuidas, si bien este control ha de constreñirse a los supuestos en que el ejercicio de las competencias de la Entidad local incida en intereses generales, concurrentes con los propios de la Entidad local, en este sentido, la sentencia del Tribunal Constitucional de 29 de abril de 1981 ha declarado que «el artículo 365, 1, en relación con el 362, 1, 4, de la Ley de Régimen local, Texto Refundido de 24 de junio de 1955, no se ajusta a la Constitución en la parte en que permite que la facultad de suspensión de los acuerdos de las Corporaciones locales proceda por la sola infracción manifiesta de las leyes, sin la concurrencia de otra circunstancia, pero sí se ajusta a la Constitución interpretado en el sentido de que confiere una facultad gubernativa para suspender acuerdos que afecten a la competencia del Estado o excedan de los límites de la competencia propia para la gestión de los intereses de la Entidad local".

Considerando: Que el Acuerdo del Pleno del Ayuntamiento de Echevarri, que aprueba el Régimen Especial de Carta propuesto para dicho Municipio por diversas coaliciones y partidos políticos, vulnera de una manera clara y patente los preceptos de la Ley de Régimen local que regulan el otorgamiento del Régimen Especial de Carta a los Municipios, al arrogarse facultades en cuanto a la aprobación de la misma, que corresponden al Consejo de Ministros, de conformidad a lo dispuesto en el artículo 96 de la Ley de Régimen local y 108 y concordantes del Reglamento de Organización, Funcionamiento y Régimen jurídico de las Corporaciones locales. (Sentencia de 14 de marzo de 1983, Ar. 1408.)

\section{Concejales: baja EN EL PARTIdo Polftico}

Considerando: Que después de sentar las anteriores conclusiones y la deducida de modo directo, en el supuesto contemplado de aplicación del artículo 23,1 , a los concejales, en virtud del artículo 140 de la Constitución, se llega a la conclusión de que el artículo 11, 7, de la Ley de Elecciones locales, en cuanto otorga a los partidos políticos la posibilidad de crear por su voluntad 
-mediante la expulsión- el presupuesto de hecho que da lugar al cese en el cargo público, vulnera un derecho fundamental susceptible de amparo, y, en consecuencia, el artículo 11,7 , ha de ser interpretado en el sentido de que no comprende el supuesto de expulsión de un partido, que no puede provocar el cese en el cargo de concejal, al ser derogado por la Constitución; en consecuencia, y de acuerdo con la doctrina sintetizada de la sentencia del Tribunal Constitucional, de 4 de febrero de 1983, procede la estimación del recurso, con revocación de la sentencia apelada y la subsiguiente nulidad del acto impugnado, por el que se acordó el cese del demandante, don Pedro C. M., como Concejal del Ayuntamiento de Sant Pere de Ribes, en cuyo cargo deberá ser repuesto. (Sentencia de 15 de marzo de 1983, Ar. 1545.)

\section{Sesiones: Comisión Permanente}

Considerando: Que esta Sala, en sentencia de 27 de octubre de 1982, contemplando la normativa referida en el artículo 213 del Reglamento de Organización, Funcionamiento y Régimen jurídico de las Corporaciones locales, a la luz de los principios de autonomía de los Municipios que consagran los artículos 137 y 140 de la Constitución, ha declarado que "la no publicidad de las sesiones a celebrar por las Comisiones Municipales Permanentes, establecida por el artículo 213 del Reglamento de Organización, Funcionamiento y Régimen jurídico de las Corporaciones locales, se opone abiertamente al principio de autonomía que para la gestión de sus respectivos intereses otorga a los Ayuntamientos la Constitución Española, y aunque, como declara la sentencia del Tribunal Constitucional -de 2 de febrero de 1981-, asi como frente a las leyes pos-constitucionales corresponde exclusivamente a dicho Tribunal enjuiciar su conformidad con la Constitución, en relación con las preconstitucionales, los Jueces y Tribunales deben inaplicarlas si entendieren que han quedado derogadas por la Constitución al oponerse a la misma». (Sentencia de 9 de febrero de 1983, Ar. 813.)

\section{QUÓRUM}

Se argumenta por la defensa de la Administración que el quórum exigido por el precepto citado se refiere exclusivamente al momento inicial en que se declara válidamente constituido el órgano colegiado del Ayuntamiento, pero no es necesario que se mantenga hasta su terminación, siendo inadmisible que pueda obstar al examen de todo el orden del día la retirada de algún concejal; problemática la expuesta que deja planteada exclusivamente la cuestión de Derecho consistente en la interpretación que ha de darse a la ordenación establecida sobre el denominado quórum de asistencia por el artículo 298, 1, antes mencionado, cuya inobservancia lleva aparejada la sanción de nulidad de pleno Derecho para los acuerdos que en la sesión se adopten, a tenor de lo que dispone el artículo 47, c), de la Ley de Procedimiento Administrativo. 
3. Y como indicó esta Sala en sentencia de 12 de febrero del corriente año, el estudio de la disposición imperativa contenida en el artículo y apartados cuestionados lleva a la conclusión de que el quórum de asistencia señalada en la misma no sólo ha de alcanzarse en el momento inicial de la sesión, como base para que el Presidente pueda declararla abierta por estar debidamente constituido el órgano colegiado, sino que ha de mantenerse durante todo su transcurso, y ello no solamente atendiendo al tenor literal del precepto, sino también a su razón de ser. (Sentencia de 18 de febrero de 1983, Ar. 907.)

\section{BIENES}

\section{RECUPERACIÓN ADMINISTRATIVA}

El Tribunal Supremo, entre otras muchas, en sentencias de 27 de enero de 1970, 29 de noviembre de 1971, 20 de mayo y 23 de octubre de 1974, 14 de octubre de 1975, 27 de abril de 1978 y 3 de abril de 1979 ha establecido la doctrina de que, dada la naturaleza privilegiada y el carácter estrictamente posesorio de la facultad de recuperación administrativa concedida en el artículo 404 de la Ley de Régimen local y 55 del Reglamento de Bienes de las Entidades locales, que en su esencia equivale a una acción interdictal emanada de su propia autoridad, su ejercicio se subordina a la existencia de una prueba plena y acabada de que el bien sobre cuya posesión se esgrime, venía sometido como de dominio público a la administración del Ente y al uso común del vecindario, y que este uso se ha visto menoscabado o usurpado por el particular contra quien se dirige la actuación. (Sentencia de 7 de febrero de 1983, Ar. 641.)

\section{EXPROPIACION FORZOSA}

\section{DERECHO ARRENDATICIO}

Considerando: Que siendo la finalidad del justiprecio indemnizar al expropiado en cuantía suficiente para adquirir otro bien análogo al que se le priva por la expropiación, sin menoscabo injusto, pero también sin enriquecimiento indebido, deben tenerse en cuenta en los arrendamientos de vivienda, para valorar la cuantía de la indemnización, las características y ubicación del piso, la situación personal del expropiado y la renta que pague por la vivienda de la que es desalojado por la expropiación. (Sentencia de 24 de marzo de 1983, Ar. 1309.) 


\section{JURADO: VALOR DE SUS ACUERDOS}

CONSIDERANDO: Que como proclama y enseña reiterada jurisprudencia, de la que constituyen exponentes, entre otras, las sentencias de 24 de febrero de 1973, 6 y 16 de noviembre de 1974 y 5 de noviembre de 1975, los acuerdos de los Jurados Provinciales de Expropiación Forzosa merecen ser acogidos con el crédito y autoridad que se desprende de su doble composición técnicojurídica y de su permanencia y especialización, lo cual, si bien no es óbice alguno para que los Tribunales de la Jurisdicción Contencioso-administrativa puedan ordenar la nulidad de sus decisiones, tiene que producirse una infracción de preceptos legales o un error o disconformidad patente con elementos de juicio que obren en el expediente o fuesen aportados a los autos, gozando dichos organismos de la Administración pública de cierta discrecionalidad técnica, a fin de concretar y determinar con exactitud el justo valor de los bienes expropiados, haciendo uso para lograr tal cometido de las facultades previstas en el artículo 43 de la Ley de 16 de diciembre de 1954. (Sentencia de 10 de marzo de 1983, Ar. 1257.)

\section{RETASACIÓN}

Considerando: Que fijado definitivamente el justiprecio en vía administrativa en 28 de enero de 1975, al ser resuelto con esa fecha el recurso de reposición y no hecha efectiva ni consignada en legal forma la cantidad señalada en el plazo de dos años establecido, en cuanto la consignación tuvo lugar, al parecer en enero de 1979, y el pago en 1 de noviembre de ese año, la solicitud de retasación en 3 de enero de 1980 debe ser atendida, máxime cuando no existe prueba alguna que acredite que la falta de efectividad del precio fuese debida a la conducta del expropiado, sin que a ello obste que el justiprecio había sido combatido judicialmente, pues, como ha declarado reiteradamente el Tribunal Supremo - sentencias de 29 de noviembre de 1972, 29 de abril de 1974, 15 de noviembre de 1978, entre otras-, «en el caso de haber sido impugnado judicialmente el justiprecio, el plazo del artículo 58 de la Ley, en relación con el artículo 35 de la misma, por tratarse de un plazo de caducidad, éste opera legalmente por el transcurso del tiempo, salvo supuestos excepcionales, y que, por tanto, la necesidad de pagar o de consignar no queda enervada por las incidencias posteriores, de modo que no abonado el justiprecio durante la tramitación de un recurso contencioso-administrativo interpuesto contra el mismo, hay que estar a la fecha en que fue señalado definitivamente en vía administrativa». (Sentencia de 18 de marzo de 1983, Ar. 1287.) 


\section{FARMACIAS}

\section{SUSPENSIÓN DE LA EJECUCIÓN DEL ACTO QUE ORDENA SU CIERRE}

Considerando: Que la clausura y cierre inmediato de una oficina de farmacia es por su propia naturaleza un acto que implica unos prejuicios evidentes, cuya cuantía es difícil prever y valorar en orden a su reparación, toda vez que el tiempo que tarde en resolverse el asunto principal está sujeto a unas contingencias que no pueden determinarse "a priori» exactamente, lo cual sitúa el supuesto contemplado en el artículo 122 de la Ley de esta Jurisdicción, al ser de imposible o, por lo menos, difícil reparación los perjuicios que se causen. (Auto de 23 de febrero de 1983, Ar. 940.)

\section{FUNCIONARIOS}

\section{CONVENIO COLECTIVO: FUNCIONARIOS PÚBLICOS: INAPLICACIÓN}

Considerando: Que ningún obstáculo afectaría a la competencia municipal (artículo 8.․ 1, del Real Decreto-ley 3/81) para concertar legales condiciones de trabajo mediante negociación colectiva, y tampoco así se aduce por el órgano de la Administración central recurrente y apelante, si el ámbito de aplicación del convenio aquí tratado se hubiese reducido a las relaciones del Ayuntamiento con su personal sujeto al Derecho laboral; del propio modo que no existiría aquel obstáculo a su competencia si la Corporación, en uso de la potestad reglamentaria aneja a su autonomía, que no es lo mismo que soberanía -artículo 140 de la Constitución-, hubiese acogido materias previamente objeto de negociación colectiva en una ordenanza organizativa del régimen interno de sus servicios a los administrados en desarrollo de, y en todo ajustado a la legalidad vigente dimanante del Estado y disposiciones reglamentarias de su Administración central en particulares de su propia competencia (arts. 103, 3, y 149, 18, de la Constitución); pero asignar al convenio colectivo la amplitud de aplicación personal transcrita en el primer considerando de esta sentencia, constituye evidente transgresión del artículo $1,3, a)$, del Estatuto de los Trabajadores aprobado por la Ley 8/1980, de 10 de marzo, a cuyo tenor se excluye de su ámbito la relación de servicios de los funcionarios públicos, asi como la del personal al servicio del Estado, las Corporaciones locales y las Entidades públicas autónomas cuando, al amparo de una ley, dichas relaciones se regulen por normas administrativas o estatutarias; y como quiera que no sólo a nivel de ley - Ley Articulada de Funcionarios Civiles del Estado de 7 de febrero de 1964, comprensiva de los Cuerpos Nacionales al servicio de la Administración local; Ley de Bases del Estatuto de Régimen local de 6 de octubre de 1977, en su parte no derogada; Ley de Régimen local, Texto Refundido de 24 de junio de 1955, y su Reglamento de Funcionarios de Administración local de 30 de mayo de 1952-, sino que incluso, al supremo rango de normas constitucionales (arts. 103, 3, y 149, 1, 18, citados), la regu- 
lación de la función pública - salvo ley que la transfiera, que aqui no existees competencia del Estado, resulta asi manifiesta la transgresión legal referida al aprobar el Ayuntamiento de Sagunto convenio colectivo que no distingue entre personal sometido al Derecho laboral y al Derecho administrativo para excluir a este último de su ámbito de aplicación, razón bastante para anular dicho acuerdo aprobatorio correctamente suspendido por el Gobernador civil y a continuación impugnado por el procedimiento especial, y de conformidad, la expresada anulación, con los artículos 83,2, y 84, a), de la Ley de lo Contencioso-administrativo. (Sentencia de 1 de marzo de 1983, Ar. 1357.)

\section{APAREJADORES: INCOMPATIBILIDADES}

ConsIderando: Que este tema ha sido ya resuelto por esta Sala en sentencias, entre otras, de 2 de febrero y 17 de abril de 1978 y 30 de junio de 1980 , que forman un cuerpo de doctrina, cuya síntesis, paralela a las cuestiones enunciadas, se resume en los tres siguientes puntos: $1 .^{\circ}$, los aparejadores municipales, que prestan los servicios propios de su profesión como funcionarios técnicos del Ayuntamiento, son incompatibles para el ejercicio libre de su profesión dentro del término de dicho Ayuntamiento, según lo dispuesto en los artículos 82 y 83, 2, de la Ley de Funcionarios Civiles del Estado de 7 de febrero de 1964, aplicables a la Administración local por remisión de los artículos 328 de la Ley de Régimen local y 37, 1, del Reglamento de Funcionarios de la Administración local de 30 de mayo de 1952; 2., el Colegio o Corporación profesional al que dicho técnico venga ligado como colegiado sometido a una relación especial de sujeción, tiene competencia para mantener el orden jurídico y deontológico de la profesión, hacer cumplir a sus colegiados las leyes generales y especiales, impedir los casos de ejercicio profesional en el que no se cumplan las disposiciones legales vigentes y velar por la firme observancia de las incompatibilidades legalmente establecidas, pues así lo previenen los artículos 5, t), de la Ley de Colegios, y 7 y 36, 1 y 12, de los Estatutos generales promulgados por el Real Decreto 1471/1977. (Sentencia de 9 de febrero de 1983, Ar. 816.)

\section{HACIENDAS LOCALES}

\section{ARbitrio de Plusvalf́a: EXPLOTACIÓN FORESTAL}

ConsIDERANDo: Que esta Sala, para casos concretos ha establecido que para que pueda hablarse de explotaciones agrícolas es necesario, además de la existencia de una organización, de la afección a la finca de medios materiales y personales, la inversión de un capital y la obtención de unos rendimientos proporcionados al capital invertido e incluso al valor del terreno; pero todos estos requisitos (no establecidos ni exigidos en la Ley de Régimen local ni en el Reglamento de Haciendas locales y, por tanto, de creación jurisprudencial), no pueden ser aplicados genérica e indiscriminadamente a toda 
clase de explotaciones, de tal forma que si no existen beneficios o éstos no se obtienen inmediatamente después de la inversión, no pueda hablarse de explotación; esto no es así, ni lo ha dicho la jurisprudencia, ni puede mantenerse, por la misma esencia de las cosas, ya que una explotación en la que se ha invertido un importante capital puede no obtener beneficios uno o varios años por circunstancias diversas, y en una explotación forestal no pueden exigirse unos beneficios en un período de tiempo distinto del que cada especie repoblada necesita para producirlos.

Considerando: Que justificada, por tanto, la realidad de la repoblación mediante documentos públicos, justificada la existencia de una organización, la inversión de un capital, la falta de rendimientos, derivada de la naturaleza de la explotación, no puede desvirtuar la existencia de una explotación forestal y, por tanto, de aquellas expresamente exentas, según el artículo 510 de la Ley de Régimen local. (Sentencia de 31 de enero de 1983, Ar. 490.)

\section{Arbitrio de plusvalfa: explotación ganadera}

ConsIDERANDo: Que para que la explotación ganadera a que, según la apelante, viene afectado el terreno objeto del arbitrio en cuestión, pudiera tener relevancia a efectos del artículo 510,1, de la Ley de Régimen local, sería necesario, tal como se resalta en la precitada sentencia de 28 de febrero de 1983, una acreditada probanza de la realidad de la mencionada explotación y, sobre todo, que ésta subsistía en los terrenos en cuestión, después de haber sido adquiridos por la sociedad constructora apelante, lo que en modo alguno aparece probado en el presente supuesto, en el que se fundamenta, esencialmente, tal afectación ganadera, en el hecho de que los terrenos gravados pertenecían antes de ser adquiridos al denominado Cortijo A., pero, insistimos, sin que se haya suficientemente acreditado que la explotación ganadera subsista después de dicha adquisición, al no aludirse a los medios y elementos, así como a los rendimientos, que en aquélla se utilicen y se obtengan. (Sentencia de 21 de marzo de 1983, Ar. 1554.)

\section{JURISDICCION CONTENCIOSO-ADMINISTRATIVA}

\section{CORPORACIÓN LOCAL: DICTAMEN PREVIO DE LETRADO}

Es condición indispensable de procedibilidad, que al acuerdo municipal decidiendo el ejercicio de una acción, debe preceder el dictamen de un Letrado de la Corporación y, en su defecto, el de un Letrado colegiado que satisfaga la correspondiente contribución sin que pueda sustituirse, como pretende la Corporación municipal apelante por el informe del Secretario del citado Ayuntamiento, aunque sea Letrado, pues ni los términos claros de dichos preceptos autorizan, aparte que sería contrario a la finalidad de la ley, que impone tal exigencia, trata de que el informe que se emite esté dotado de la objetividad e imparcialidad precisos al interés del Municipio, para asegurar la serenidad 
de juicio que todo informe jurídico requiere, como así lo tienen ya declarado reiteradas sentencias de este Tribunal, entre otras, la de 12 de diciembre de 1977 y demás que se citan en la sentencia apelada. (Sentencia de 10 de febrero de 1983, Ar. 598.)

\section{2. «SOLVE ET REPETE»}

La más reciente doctrina de nuestro Tribunal Supremo, recogida, entre otras, en sentencias de 14 y 27 de junio de 1973, 20 de noviembre de 1974, 15 de junio y 22 de noviembre de 1976, ha venido a reconocer que el requisito del "solve et repete» es una norma de reenvio o en blanco que precisa de una ley formal que lo establezca en cada materia concreta, y en el presente caso, al Reglamento de Organización, Funcionamiento y Régimen jurídico de las Corporaciones locales, aprobado por Decreto de 17 de mayo de 1952, no es posible reconocer tal rango normativo, por lo que no puede atribuirse a la omisión de pago aducida, la consecuencia de la inadmisión del recurso, que, como tiene señalado nuestro Tribunal Supremo, ha de ser siempre objeto de interpretación restrictiva -sentencia de 5 de mayo de 1978-. (Sentencia de 5 de enero de 1983, Ar. 242.)

\section{POLICIA MUNICIPAL}

\section{ACTIVIDADES MOLESTAS, INSALUBRES, NOCIVAS Y PELIGROSAS: MEDIDAS CORRECTORAS: SALIDA DE URGENCIA}

Las salidas que, en proporción a la capacidad de espectadores, se prevén para tales edificios, han de ser salidas a vias públicas (art. 117) o calles (artículo 120), lo cual es de una lógica y de una necesidad evidentes, puesto que sólo con salida a espacio libre puede el local desocuparse en el breve espacio de tiempo que imponga cualquier catástrofe o anormalidad. De donde se sigue que, a pesar del laconismo con que esta exigencia fue impuesta por la citada Comisión, ha de concluirse que, puesto que se impuso, lo fue con la finalidad ordinaria y normal de las salidas de emergencia, es decir, la de facilitar a los usuarios del local una salida suplementaria a la vía pública, en evitación o aminoración de las conocidas catástrofes que pueden sobrevenir en los locales destinados al público.

CONSIDERANDO: Que el incumplimiento de la medida correctora de la falta de salida del local de autos a una vía pública no puede estimarse cumplida con el acceso a un patio de la casa o establecimiento, ni puede entenderse referida exclusivamente a una segunda licencia de funcionamiento de la cafeteria, con independencia de la licencia de instalación, pues ello privaria al Ayuntamiento concedente de la licencia discutida de las facultades inspectoras y de policia que le confieren de consuno, tanto la Ley de Régimen local, como el Reglamento de Actividades molestas, insalubres, nocivas y peligrosas de 
30 de noviembre de 1961 y las instrucciones para su aplicación de 15 de marzo de 1963, en las que se especifica que ninguna industria o actividad podrá empezar a funcionar sin la adopción de las medidas correctoras. (Sentencia de 4 de enero de 1983, Ar. 170.)

\section{LICENCIAS: COMPETENCIA MUNICIPAL}

Debe ceder ante el régimen legal del suelo y ordenación urbana contenido en el Texto Refundido citado y disposiciones complementarias $y$, en los artículos 57 y 178 de dicho Texto; 1, 6 y 7 del Reglamento de Disciplina Urbanística, y 1, 3., del Reglamento de Servicios de las Corporaciones locales, que imponen a los Ayuntamientos y a los particulares la obligación inexcusable de cumplir la legalidad urbanística y conceden a aquéllos la potestad de someter a previa licencia los actos de edificación y uso del suelo que se realicen dentro de su término, al que se extiende la aplicación de los Planes generales municipales y, desde luego, la propia Ley del Suelo; debiendo destacarse que en tal sentido, el artículo 1, 1, del Reglamento de Disciplina Urbanistica habla de "toda clase" de obras de construcción de edificaciones e instalaciones de nueva planta, comprendiendo en su número 7 "las obras de instalación de servicios públicos», e incluso en su artículo 7, las obras promovidas por el mismo Estado, poniéndose asi de manifiesto por ese contexto normativo, que preside el mencionado Texto Refundido, un principio de competencia municipal sin limitación territorial alguna que debe prevalecer sobre la legislación especial de las industrias eléctricas por la simple razón de que ese Texto es de fecha posterior, constituye el régimen legal específico en materia urbanistica $e$ incluye una disposición final derogatoria de cuantas disposiciones se opongan a lo establecido en el mismo, y que ello debe ser así lo confirma la consideración de que la tesis contraria mantenida en la sentencia apelada conduce al resultado inaceptable de dispensar a las empresas eléctricas de la observancia de la Ley del Suelo y de los Planes de Ordenación Urbana, permitiéndoles realizar en suelo rústico sus instalaciones con total frustración de las previsiones urbanísticas establecidas en dicha Ley y Planes, cuando ni siquiera la instalación de servicios públicos y realización de obras por el propio Estado están exentas de dicho cumplimiento, ni de la obligatoriedad de obtener la previa licencia municipal, cuya necesidad en todos los supuestos de actos de edificación y uso del suelo proclamada en los textos legales y reglamentarios citados, se hace más incuestionable desde que el artículo 140 de la Constitución Española garantiza la autonomía municipal; conclusión que se refuerza a la vista del artículo 30 del Reglamento de 30 de noviembre de 1961, al amparo del cual el Ayuntamiento encontraría, en último término, cauce normativo para oponerse eficaz y lícitamente a la instalación de autos por razones de competencia municipal basadas en los Planes y Ordenanzas municipales. (Sentencia de 9 de marzo de 1983, Ar. 1399.) 


\section{LICENCIAS DE OBRAS: PROCEDIMIENTO}

En los expedientes instruidos para el otorgamiento de las licencias de obras, exigida por el artículo 178 del Texto Refundido de la Ley del Suelo, y a desarrollar conforme al procedimiento regulado en el artículo 9.' del Reglamento de Servicios, no es precisa la audiencia de las personas supuestamente afectadas por la edificación u obra proyectada, puesto que las mismas no ostentan, en tesis general y a salvo supuestos especiales, ningún derecho subjetivo de carácter negativo, y solamente en el caso de que se hubieran personado espontáneamente en el expediente de concesión de la licencia cabría estimarlas como parte interesada, a efectos de lo dispuesto en el artículo 91 de la Ley de Procedimiento Administrativo, todo ello de conformidad con lo dispuesto en los artículos 23 y 26 del mismo Texto legal, y sin que esta normativa suponga hoy en dia indefensión alguna en materia de urbanismo para los intereses legitimos comprometidos, puesto que la acción impugnatoria -públi$c a$, por otra parte-de licencias ilegales puede promoverse hasta un año después de concluidas las obras, según determina el artículo 235, 2, de la Ley del Suelo. (Sentencia de 8 de marzo de 1983, Ar. 1393.)

\section{LICENCIAS DE OBRAS: SUSPENSIÓN POR EL ALCALDE}

Para la viabilidad de la suspensión de los efectos de una licencia de obras apoyada en lo dispuesto en el artículo 186 de la Ley del Suelo, se requiere la concurrencia de una serie de requisitos objetivos primordialmente, aparte de que se trate de uno de los actos concretamente recogidos en el artículo 178 del citado Texto legal, que el contenido del acto accesorio de licencia constituya una infracción urbanistica grave, o sea, una de las contempladas en el artículo 226 de la norma indicada, y, además, que tal infracción resulte de una manera patente, notoria, evidente, incontrovertible, o lo que es to mismo, que para apreciarla no haya de recurrirse a interpretaciones analógicas o extensivas o a razonamientos jurídicos prolijos $e$ intrincados, siendo exigible, por consiguiente, que aquella infracción se deduzca de un enfrentamiento del texto del acuerdo con la literal de las normas incumplidas o, al menos, con su interpretación lógica y natural. (Sentencia de 25 de marzo de 1983, Ar. 1577.)

\section{OBRAS SIN LICENCIA: DEM OLICIÓN}

Entrando a examinar la cuestión suscitada sobre si el Alcalde tiene competencia para ordenar la demolición de lo construido o si, por el contrario, tal competencia le corresponde al Ayuntamiento, la misma hemos de resolverla en contemplación de lo establecido en los párrafos 3 y 4 del artículo 184 de la vigente Ley del Suelo, a tenor de los cuales inicialmente es al Ayuntamiento a quien corresponde ordenar la demolición, transcurrido que ha sido el plazo de dos meses, a que se refiere el apartado 2, o desde que la licencia fuera denegada; pero esta facultad debe ser ejercida en el plazo de un mes, contado 
desde la expiración del término a que antes nos hemos referido, ya que transcurrido dicho mes sin haberla acordado, y según el número 4 del artículo que estamos examinando, es el Alcalde quien dispondrá directamente dicha demolición a costa del intéresado. (Sentencia de 12 de febrero de 1983, Ar. 1031.)

\section{RUINA: CONCEPTO}

Suponiendo toda declaración de ruina desde un punto de vista teleológico, el acto jurídico de determinar e investigar el estado de hecho que mantenga realmente el inmueble de que se trate, de tal modo que comprobado verazmente, que puede ser catalogado en algunos de los supuestos que contempla el artículo 183, 2, de la Ley del Suelo de 9 de abril de 1976, Texto Refundido, cualesquiera que sean las causas que hubieren motivado tal situación fáctica y la calificación que merezca la conducta seguida por el propietario de la finca, ha de resolverse mediante la valoración de cuantos elementos de prueba existan, entre los que tendrán gran importancia las periciales practicadas, que deberán interpretarse por la Sala de acuerdo con los criterios de la sana critica, como establece el artículo 632 de la Ley de Enjuiciamiento Civil y jurisprudencia del Tribunal Supremo dictada en torno a dicho precepto. (Sentencia de 17 de febrero de 1983, Ar. 905.)

\section{RUINA: CLASES}

Contempla tres supuestos de ruina: física, cuando los daños que presente la finca no sean reparables técnicamente por los medios normales, es decir, cuando los daños afecten a elementos estructurales, tales como cubiertas, muros, forjados, cimientos, etc., y la única solución para hacerlos desaparecer es su demolición y reconstrucción; económica, cuando los daños o deficiencias, entre las que hay que incluir las que afectan a la salubridad, si sean reparables técnicamente por medios normales, pero el importe de los mismos exceda del 50 por 100 del valor actual del edificio, excluido el del solar, y urbanística, cuando concurran circunstancias de tal naturaleza que aconsejen la demolición del inmueble; no es necesario la concurrencia de los tres o dos de los supuestos indicados, basta uno solo para tenerse que declarar la ruina, salvo el caso de ruina urbanistica que tiene que concurrir con una ruina física o con una ruina económica o con las dos - sentencias del Tribunal Supremo de 3, 10, 15 y 22 de noviembre de 1980-. (Sentencia de 28 de enero de 1983, Ar. 371.)

\section{RUINA: MEDIOS NO NORMALES DE REPARACIÓN}

Entiende la jurisprudencia que "cuando hay que reconstruir»-cual aquí ocurre-, "aunque sólo sea en parte, no puede decirse que los medios reparatorios sean normales» - sentencia de 28 de noviembre de 1975-, implicando la "reconstrucción" la utilización de medios extraordinarios - sentencia de 
3 de junio de 1975-, y reiterando las sentencias del Tribunal Supremo de 27 de octubre de 1975 y 31 de diciembre de 1974 que «los medios normales se relacionan con la reparación simple y los medios no normales con la reconstrucción"; procediendo, desde luego, la declaración de ruina -dicen las dos últimas sentencias citadas-, si se trata de obras de reconstrucción de elementos arquitectónicos esenciales y costosos, como lo es la techumbre; añadiendo otra sentencia de 29 de octubre de 1975, que también lo son los muros generalmente agrietados y los suelos abombados. (Sentencia de 5 de enero de 1983, Ar. 237.)

\section{RUINA URBANÍSTICA}

El mero hecho de encontrarse una edificación en unas determinadas circunstancias urbanísticas, no configura por sí solo la declaración de estado de ruina, en aplicación de lo dispuesto en el apartado c) del artículo 183 de la Ley de Régimen del Suelo, ya que para la viabilidad de esta causa no basta la simple existencia de la misma, sino que tal hecho ha de estar en intima conexión con la situación o estado físico de dicha edificación, que requiera para restablecer su normalidad en orden a la seguridad y salubridad, unas obras que por su volumen y trascendencia excedan de las autorizables, a tenor de lo dispuesto en el artículo 60 de la mencionada Ley del Suelo, según doctrina de esta Sala contenida, entre otras, en las sentencias de 28 de noviembre de 1975 , 20 de junio de 1977, 1. ${ }^{\circ}$ de junio de 1979, 7 de marzo de 1980, 21 de enero de 1981 y 22 de febrero de 1982. (Sentencia de 24 de enero de 1983, Ar. 292.)

\section{PROCEDIMIENTO ADMINISTRATIVO}

\section{AUDIENCIA DE LOS INTERESADOS EN EL EXPEDIENTE}

La audiencia de los interesados en el expediente administrativo no es considerada por nuestro ordenamiento como un rito formal y solemne cuya omisión provoque automáticamente la nulidad de la resolución adoptada, sino como trámite instrumental cuya finalidad es posibilitar a los afectados por cualquier expediente administrativo la introducción en el mismo de cuantos elementos estimen pertinentes para su más adecuada resolución, por lo cual, como declara la sentencia de 10 de junio de 1974, la jurisprudencia no contempla los supuestos de modo unánime empleando un rigor formalista que seria desaconsejable, sino que examina las circunstancias del caso en orden a evitar que se produzca indefensión, razón por la que el motivo no aparece en la lista tasada de causas que producen la nulidad de pleno derecho, relacionadas en el artículo 47 de la Ley de Procedimiento Administrativo, lo que implica que dicha ausencia tenga que ser encuadrada como uno de los supuestos que pueden producir la anulabilidad del acto dentro de la causa genérica contemplada en el artículo 48 de la misma Ley, habiendo declarado reiteradamente la jurisprudencia — sentencias de 31 de noviembre de 1975 . 
21 de marzo de 1976, 23 de marzo y 18 de mayo de 1977, 11 de marzo de 1978 y 18 de abril de 1979- que no se produce indefensión y, en consecuencia, no procede decretar la anulabilidad, si los interesados han podido acudir al recurso de reposición $y$ después al contencioso $y$ han tenido oportunidad de alegar en ellos lo que entienden conveniente a sus intereses. (Sentencia de $7 \mathrm{de}$ marzo de 1983, Ar. 1378.)

\section{RESPONSABILIDAD}

\section{De la ADMinistración local}

El tema de la responsabilidad patrimonial de la Administración local viene contemplado inicialmente en los artículos 405 y siguientes de la Ley de Régimen local, que fueron cabalmente los preceptos que introdujeron en nuestro ordenamiento juridico-administrativo el principio de la responsabilidad objetiva de la Administración, anticipando asi en el ámbito local, como recuerda la sentencia del Tribunal Supremo de 5 de noviembre de 1979, lo que más tarde se extendió a la esfera central en virtud de lo dispuesto en los artículos 121 de la Ley de Expropiación Forzosa y 40 de la Ley de Régimen juridico de la Administración del Estado, que completan la definitiva consagración legislativa a dicho principio, que actualmente alcanza su máximo rango normativo en el artículo 106, 2, de la Constitución; no debiendo olvidarse que la inicial regulación contenida en la Ley de Régimen local ha venido a ser superada en ciertos aspectos por el articulo 121 de la Ley de Expropiación Forzosa y el artículo 132 de su Reglamento; de ahi que, entre otros efectos, como dice la sentencia de 23 de marzo de 1979, la distinción entre responsabilidad directa y subsidiaria, a que hacen referencia los artículos 405, 406 y 409 de la Ley de Régimen local ha perdido entidad a la vista de lo establecido en el artículo 121 de la Ley de Expropiación Forzosa, donde se establece la responsabilidad de la Administración de modo directo y en forma objetiva, tanto para el supuesto de un funcionamiento normal como anormal de la Administración, si de ello resulta daño para los administrados, quedando marginada la licitud - la ilicitud de su actuar o el que se produzca por actos u omisiones puramente materiales o de hecho, bastando con que causen perjuicios a los administrados -postura que empieza a abrirse paso, y de ello es ejemplo la sentencia de 15 de noviembre de 1962, y que adquiere carta de naturaleza en las de 14 de octubre de 1969 y 27 de enero de 1971-, con lo que indudablemente se ha dado entrada a criterios de responsabilidad objetiva; por lo que cabe afirmar, recogiendo la doctrina de la sentencia de 23 de enero de 1970, que ya no se requiere en este tipo de pretensiones la concurrencia de aquellos tres clásicos requisitos, tomados del campo civil, de realidad del daño, culpa o negligencia y relación de causalidad entre aquél y la acción u omisión culposa o negligente, sino que, conforme a la actual normativa, hay que estimarlos modificados en el sentido de que la efectiva realidad del daño singularizado no sea consecuencia de fuerza mayor o culpa de la victima y proceda del funcionamiento de los servicios públicos en relación de causa a efecto, sin inter- 
ferencias en el nexo causal, correspondiendo la prueba del daño y su origen al reclamante, y la de los hechos impeditivos de la pretensión, fuerza mayor y culpa del administrado, a la Administración demandada. (Sentencia de 4 de febrero de 1983, Ar. 551.)

\section{SERVICIOS}

\section{RECOGIDA DE BASURAS: RESOLUCIÓN DE CONTRATO}

No puede enervar el cumplimiento de las obligaciones contraídas por la Empresa E., S. A., en cuanto a la recogida de basuras y limpieza viaria de Gijón, la huelga de los trabajadores encargados de realizar tales servicios, ya que este suceso no aparece recogido entre los casos que el ordenamiento legal en materia de contratación administrativa considera de fuerza mayor. (Sentencia de 21 de enero de 1983, Ar. 279.)

\section{Teléfonos: facultades de la Compañfa Telefónica Nacional DE EsPaÑa Y DE LOS AyUNTAMIENTOS}

El derecho de la Compañía Telefónica a instalar cualquiera de los elementos de que precise el servicio que tiene concedido, ha de entenderse sin merma de la competencia de la Administración local para ejercer todas las potestades que conlleva en orden a los fines generales que le están encomendados, ya sea en materia urbanística, de tráfico o en interés del Municipio, por lo que es patente que conserva las de revocación de la autorización cuando aquéllos lo exijan, pero asimismo, y por imperativo de los artículos 1 y 4 del citado Decreto, cuando la revocación o retirada requiera el cambio de emplazamiento de la conducción ahora autorizada, el coste que la modificación comporte habrá de ser sufragado por mitad entre la Entidad a que la iniciativa corresponda y a la citada Compañía. (Sentencia de 4 de enero de 1983, Ar. 169.)

\section{TERMINOS MUNICIPALES}

\section{DESLINDES}

"La jurisprudencia del Tribunal Supremo tiene declarado en numerosas sentencias, entre las que se encuentran las de 23 de octubre de 1902; 20 de marzo y 15 de noviembre de 1928; 18 de enero, 6 de mayo y 2 de octubre de 1936, y 4 de junio de 1941, que la Administración para resolver los expedientes de deslinde ha de basarse, en primer lugar, en lo que resulte de deslindes anteriores, practicados de conformidad con los Municipios interesados y que, solo a falta de documentos comprensivos de deslindes anteriores, deberán tenerse en cuenta aquellos otros documentos que, aun no siendo de deslinde, 
expresen de modo preciso la situación de los terrenos en cuestión $y$, por último, los que resulten de fincas o heredades que se encuentren enclavadas en el terreno litigioso, y demás pruebas que contribuyan a formar juicio sobre la cuestión planteada y de los que pueda deducirse con certeza a cuál de las partes favorece la posesión de hecho". (Sentencia de 26 de febrero de 1983, Aranzadi, 1058.)

\section{TRAFICO}

\section{ESCUELAS DE CONDUCTORES: LUGARES PARA PRÁCTICAS}

La Orden de 18 de junio de 1978 estableció que en el supuesto de que las mencionadas Escuelas no posean el terreno exigido, en cuyo caso detalla que deberán disponer de autorización municipal para realizar las prácticas en determinadas calles o zonas que reunan las condiciones adecuadas, según lo previsto en el artículo 275 del vigente Código de la Circulación; el otorgamiento, pues, de estas licencias municipales no es discrecional, sino reglado, debiendo los Ayuntamientos concederlas, determinando las calles o zonas en que tales prácticas puedan efectuarse. (Sentencia de 20 de enero de 1983, Ar. 277.)

\section{URBANISMO}

\section{ESTUDIO DE DETALLE: NO SON IMPUGNABLES}

Considerando: Que los estudios de detalle, cuya formación se regula en el artículo 40, en relación con el 41, del Texto Refundido de la Ley del Suelo, y en el 140 del Reglamento de Planeamiento, suponen un acuerdo de aprobación inicial que, por su naturaleza de acto de trámite, puesto que sólo determina el paso al estado siguiente del procedimiento, no es impugnable en la vía gubernativa ni en la judicial -artículos 113 de la Ley de Procedimiento Administrativo y 37 de la Jurisdiccional-. (Sentencia de 5 de enero de 1983, Aranzadi 238.)

\section{Licencia QUe infringe el Plan: suspensión}

La licencia concedida constituye una infracción urbanistica, ahora bien, para que la actuación de la autoridad administrativa suspendiendo sus efectos sea legitima, es necesario que la infracción sea manifiesta y grave, requisitos que concurren en el caso de litis, por cuanto, en relación con el primer requisito, la concesión de una licencia para la construcción de un edificio en terreno que, según el Plan general, no merece la calificación de solar, ni siquiera de suelo urbano, por ser de reserva urbana, constituye una ilegalidad urbanistica 
que debe entenderse clara y evidente, pues basta para evidenciarla la simple contemplación de la normativa expuesta y la situación de hecho del terreno calificado de reserva urbana en el Plan General de Ordenación; y en relación con el segundo requisito, la gravedad de la infracción se deduce del hecho de amparar tal licencia la construcción de un edificio que con arreglo a tal normativa no podia concederse, por lo que su construcción constituye una infracción subsumible en los supuestos típicos del artículo 226, 2, de la Ley del Suelo, por incumplir las normas relativas al uso del suelo, volumen y altura. (Sentencia de 9 de marzo de 1983, Ar. 1396.)

\section{Revision Del Plan general: Facultades MUNicipales}

1. El Plan metropolitano de Barcelona de 14 de julio de 1976 realiza, de conformidad con lo dispuesto en el Decreto-ley 5/74, de 24 de agosto, una revisión general del planeamiento anterior según nuevos criterios de reestructuración general $y$ orgánica del territorio, habiendo sido aprobado por los brganos competentes dentro del procedimiento legalmente establecido. $2 .^{\circ}$ La Administración ha ejercitado en dicho Plan la potestad innovadora que le concede el artículo 47 del Texto Refundido de la Ley del Suelo, la cual no encuentra limite en los derechos adquiridos al amparo del planeamiento anterior, en cuanto que éstos sólo pueden dar lugar, en su caso y en el momento de la ejecución del Plan, a las indemnizaciones que resulten procedentes por la via de expropiación o a través de los instrumentos de justa distribución de los beneficios y cargas que correspondan, y que contempla el Texto citado. $3 .^{\circ}$ Las determinaciones de carácter general y las calificaciones del suelo que se adopten en el ejercicio de esa facultad revisoria dentro del contexto de dicho Plan, deben ser mantenidas por esta jurisdicción, mientras no se acredite de manera fehaciente la concurrencia de desviación de poder o la improcedencia de las mismas. (Sentencia de 20 de enero de 1983, Ar. 283.)

\section{VIVIENDA}

\section{Facultades de las Delegaciones PRovinciales: ascensores}

Las competencias en la materia de que aqui se trata-reparación de un ascensor-, de los ramos de Vivienda e Industria, son "armónicas, paralelas $y$ combinadas", de suerte que el primero "posee plena potestad para que se vuelva a prestar un servicio que necesaria $y$ directamente repercute en las condiciones de utilización de un inmueble en el que existen diferentes viviendas, como es el del ascensor, que tratándose de pisos altos desborda el concepto de la simple comodidad y penetra en el de la salubridad", e intervinien- 
do el segundo al "procederse al cumplimiento del mandato administrativo de vivienda, en cuanto a las técnicas de seguridad y buen funcionamiento de las instalaciones y aparatos del servicio que supone el ascensor". (Sentencia de 9 de febrero de 1983, Ar. 811.)

NEMEsIo Rodriguez MoRo 